\title{
A single dose comparison of a combination of fenoterol and ipratropium aerosols in bronchial asthma
}

\author{
P. LAWFORD* \\ M.B., M.R.C.P. \\ K. N. V. PALMER \\ M.A., M.D., F.R.C.P. \\ Pulmonary Function Room, University of Aberdeen, Foresterhill, Aberdeen AB9 2ZD
}

\begin{abstract}
Summary
Nine patients with reversible obstructive airways disease were studied to compare the bronchodilator response to a combination of fenoterol and ipratropium aerosols with two dose levels of fenoterol alone.

Using a double-blind, cross-over, single dose regime, $200 \mu \mathrm{g}$ fenoterol hydrobromide and $80 \mu \mathrm{g}$ ipratropium bromide was compared to $\mathbf{4 0 0} \mu \mathrm{g}$ fenoterol + placebo, and to $200 \mu \mathrm{g}$ fenoterol + placebo.

There was no significant difference between the combination and either dose of fenoterol in terms of peak or duration of response as determined by absolute or percent change in forced expiratory volume in one second, or forced vital capacity, over baseline.
\end{abstract}

KEY WORDS: bronchodilator, fenoterol, ipratropium, aerosol.

\section{Introduction}

Since its introduction ipratropium bromide has been recommended for the treatment of chronic bronchitis (Crompton, 1980) but its place in the management of reversible airflow obstruction remains uncertain (Cole, 1981) and it is not clear whether the combination with a $\beta_{2}$ agonist has any advantage over individual drugs.

This study sought to determine whether the combination of ipratropium bromide and fenoterol produced greater bronchodilator response than fenoterol alone in patients with chronic asthma.

\section{Patients and methods}

Nine patients of mean age 56 (45-66) attending the Asthma Clinic took part in a single-dose, doubleblind crossover study which had the approval of the Hospital's Ethical Committee. All gave a history of chronic or episodic wheeze and their forced expiratory volume in one second $\left(\mathrm{FEV}_{1}\right)$ improved by $15 \%$ or more after two puffs isoprenaline or salbutamol.

\footnotetext{
*Present address: The Chest Clinic, Coventry and Warwickshire Hospital, Coventry CVI 4FH.
}

Their initial FEV, was less than $80 \%$ predicted anc all had good timing of aerosol release. They attendect. on three separate occasions a week apart and omittede bronchodilator therapy for $9 \mathrm{hr}$ before attendance none was receiving a slow-release oral theophylline preparation. Nine continued to take inhaled steroidspo six oral corticosteroids and one sodium cromoglycate은 Two patients had positive prick skin tests to commonallergens.

After baseline measurements of $\mathrm{FEV}_{1}$, forced vita capacity (FVC) (Vitalograph-best of three readings and pulse rate, they received four puffs of aerosol on each occasion at the same time of day from maske inhalers according to a randomized plan.

The dose of ipratropium bromide used in combination was higher than the manufacturer recommended dose, as suggested by Allen anc Campbell (1979). This was compared with two doseso of fenoterol; $400 \mu \mathrm{g}$ being the recommended dose and $200 \mu \mathrm{g}$ matching the dose in the combination.

Treatment day A: 2 puffs $\times 100 \mu \mathrm{g}$ fenoterol +2 puffs $\times 40 \mu \mathrm{g}$ ipratropium;

B: 2 puffs $\times 200 \mu \mathrm{g}$ fenoterol +2 puffs placebo;

C: 2 puffs $\times 100 \mu \mathrm{g}$ fenoterol +2 puffs placebo.

Patients inhaled at their usual inspiratory flow rate from residual volume to total lung capacity; breath-:holding time was $4 \mathrm{sec}$. Aerosol release was patient 3 . activated. Subsequent measurements of pulse, FEV and FVC were made at $\frac{1}{2}, 1,2,3,4,5,6$ and $7 \mathrm{hr}$ after aerosol administration, the latter being expressed aso litres (ATPS).

Statistical analysis of absolute change was byo analysis of variance (Table 1 ) and $t$-testing using residual variation.

Mean initial FEV, was 1.02 litres (41\% predicted) and there was no difference in mean initial FEV, on any treatment day.

\section{Results}

The mean baseline and maximum increment 0 values of FEV, and FVC on the three drug regimens? are shown in Table 1. 
TABLE 1. Mean ( \pm s.e.m.) baseline and maximum increments (l) in FEV, and FVC after the three treatments

\begin{tabular}{|c|c|c|c|c|}
\hline & \multicolumn{2}{|r|}{$\mathrm{FEV}_{1}$} & \multicolumn{2}{|r|}{ FVC } \\
\hline & Baseline & Maximum increment & Baseline & Maximum increment \\
\hline \multirow{2}{*}{$\begin{array}{l}\text { Fenoterol } 200 \mu \mathrm{g} \\
\text { Fenoterol } 400 \mu \mathrm{g} \\
\text { Fenoterol } 200 \mu \mathrm{g} \\
\text { Ipratropium } 80 \mu \mathrm{g}\end{array}$} & $\begin{array}{l}0.97 \pm 0 \cdot 10 \\
1 \cdot 12 \pm 0 \cdot 14\end{array}$ & $\begin{array}{l}0.49 \pm 0.09 \\
0.56 \pm 0.07\end{array}$ & $\begin{array}{l}1.87 \pm 0.15 \\
1.96 \pm 0.20\end{array}$ & $\begin{array}{l}0.63 \pm 0.10 \\
0.73 \pm 0.11\end{array}$ \\
\hline & $0.97 \pm 0.08$ & $0.49 \pm 0.06$ & $1 \cdot 83 \pm 0 \cdot 16$ & $0.72 \pm 0.11$ \\
\hline
\end{tabular}

Absolute FEV, levels were significantly higher than baseline for all three treatment days up to and including $7 \mathrm{hr}$ post-administration $(P<0.05)$. There were no significant differences between the three treatments with respect to either absolute or percent change for baseline.

Absolute FVC levels were significantly higher than baseline at the $5 \%$ level for the combination up to 7 $\mathrm{hr}$ post-administration, for fenoterol $200 \mu \mathrm{g} \times 2$ up to $6 \mathrm{hr}$ and up to $5 \mathrm{hr}$ for fenoterol $100 \mu \mathrm{g} \times 2$. There were no significant differences between the three treatments in terms of absolute or percentage change from baseline. The percentage changes in FVC and FEV , are shown in Figs 1 and 2 respectively.

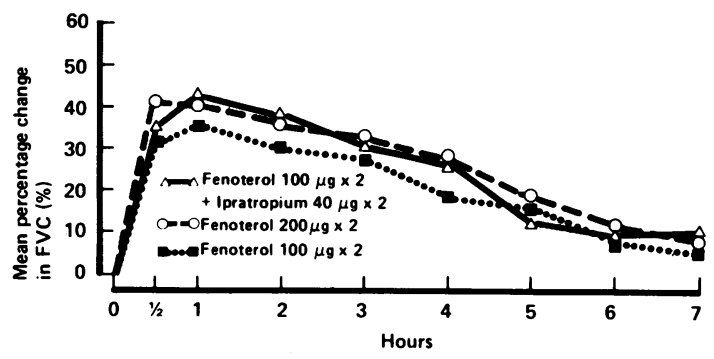

Fig. 1. Mean percentage change in FVC up to $7 \mathrm{hr}$ after fenoterol and placebo and a combination of fenoterol and ipratropium.

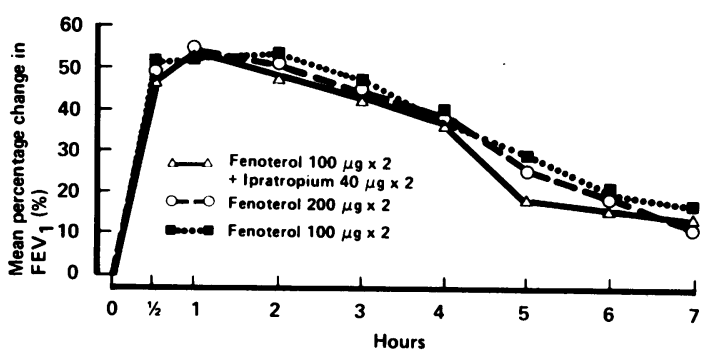

FIG. 2. Mean percentage change in FEV, up to $7 \mathrm{hr}$ after fenoterol and placebo and a combination of fenoterol and ipratropium
There were no significant differences in mean absolute change in pulse rate between any of the three treatment days.

\section{Discussion}

Prolonged effect is a desirable property for an aerosol bronchodilator. Fenoterol hydrobromide has been shown to have a significant effect up to $4 \mathrm{hr}$ in recommended dosage (Plit et al., 1972; Lawford, Dowd and Palmer, 1981) although there is some evidence of longer duration (Anderson, Wilkins and Jariwalla, 1979; Benjamin, 1972). Ipratropium bromide has likewise been found to have a significant bronchodilator effect up to $4 \mathrm{hr}$ (Gross, 1975) in a dosage of $20 \mu \mathrm{g}$ and a significant prolongation of response with higher dosage (Baigelman and Chodosh, 1977; Allen and Campbell, 1979).

This study has shown that a combination of $200 \mu \mathrm{g}$ fenoterol with $80 \mu \mathrm{g}$ ipratropium gives comparable duration of response to $400 \mu \mathrm{g}$ fenoterol alone, and is slightly superior to $200 \mu \mathrm{g}$ fenoterol alone in terms of FVC response over baseline at 6 and $7 \mathrm{hr}$, although this may not represent a significant clinical improvement.

Although an additive effect on peak bronchodilator response has been shown for a combination of wet nebulized atropine and salbutamol using cumulative dosing (Pierce, Allen and Campbell, 1979), and for ipratropium and salbutamol using a sequential study in bronchitis (Douglas et al., 1979) and over a 3 day period in both an asthmatic and bronchitic group (Lightbody et al., 1978) no significant increase in duration of response has been found in single dose studies combining ipratropium and $\beta_{2}$ agonist compared to either drug alone (Petrie and Palmer, 1975; Ruffin, Fitzgerald and Rebuck, 1977).

Further combination studies are needed in patients with steroid-unresponsive airflow obstruction, particularly as ipratropium may produce a comparable or greater response in chronic bronchitis than $\beta_{2}$ sympathomimetic drugs (Altounyan, 1964; Crompton, 1968; Poppius and Salorinne, 1973). 


\section{Acknowledgments}

To G. Cox, D. Alston, A. Eyre-Brook and Miss E. Allan of W.B. Pharmaceuticals for supply of inhalers and statistical assistance.

\section{References}

ALLEN, C.J. \& CAMPBELL, A.H. (1979) Dose response of ipratropium bromide assessed by two methods. Thorax, 34, 137.

Altounyan, R. (1964) Variation of drug action on airway obstruction in man. Thorax, 19, 406.

ANDERSON, G., Wilkins, E. \& JARIWAlla, A.G. (1979) Fenoterol in asthma. British Journal of Diseases of the Chest, 73, 81.

BAigelmaN, W. \& CHODOSH, S. (1977) Bronchodilator action of the anticholinergic drug ipratropium bromide (SCH 1000) as an aerosol in chronic bronchitis and asthma. Chest, 71, 324.

BENJAMIN, C. (1972) A comparative study of the bronchodilator effects of five $\beta$-adrenoceptor stimulant drugs in patients with reversible broncho-obstruction. Medical Proceedings, 18, 35.

CoLE, R.B. (1981) Drug treatment of respiratory disease. In: Monographs in Clinical Pharmacology, 5 (Ed by Azarnoff, D.L.), Churchill Livingstone, London.

Crompton, G.K. (1980) In: Diagnosis and Management of Respiratory Diseases, Blackwell Scientific Publications, Oxford, p. 29.

Crompton, G.K. (1968) A comparison of bronchodilator drugs in chronic bronchitis and chronic asthma. Thorax, 23, 46.
Douglas, N.J., Davidson, I., Sudlow, M.F., \& Flenley, D.C (1979) Bronchodilation and the site of airway resistance in seve $\mathbb{8}$ chronic bronchitis. Thorax, 34, 51.

Gross, N.J. (1975) Sch.1000: A new anti-cholinergic bronchodilator. American Review of Respiratory Diseases, 112, 823.

LAWFORD, P., DowD, D.E. \& PALMER, K.N.V. (1981) A comparison of the duration of action of fenoterol and salbutamol in asthma Current Medical Reseach and Opinion, 7, 349.

LightBODY, I.M., INGRAM, C.G., LEGGE, J.S. \& JOHNSTON, R.N (1978) Ipratropium bromide, salbutamol and prednisolone in bronchial asthma and chronic bronchitis. British Journal fo Disease of the Chest, 72, 181.

Petrie, G.R. \& Palmer, K.N.V. (1975) Comparison of aerosol ipratropium bromide and salbutamol in chronic bronchitis an asthma. British Medical Journal, 1, 430.

Pierce, R.J., Allen, C.J. \& Campbell, A.H. (1979) A comparatives study of atropine methonitrate, salbutamol and their combinatiog in airways obstruction. Thorax, 34, 45.

Plit, M., Goldman, H.I., Cassel, M.L. \& Zwl, S. (1972) The bronchodilator action of fenoterol (Berotec) in asthma. Medic לुb Proceedings, 18, 41.

PoPPIUS, H. \& SALORINNE, Y. (1973) Comparative trial of a new anticholinergic bronchodilator Sch.1000 and salbutamol i. chronic bronchitis. British Medical Journal, 4, 134.

RufFIN, R.E., FITZGERALD, J.O.\& REBUCK, A.S. (1977) A compario son of the bronchodilator activity of Sch.1000 and salbutamo? Journal of Allergy and Clinical Immunology, 59, 136.

(Accepted 6 July 1982) 